\title{
Three patients presenting with severe macrosomia and congenital hypertrophic cardiomyopathy: a case series
}

\author{
Marie Vincent ${ }^{1 *} \mathbb{D}$, Nadir Benbrik², Bénédicte Romefort ${ }^{2}$, Agnès Colombel $^{3}$, Stéphane Bézieau ${ }^{1}$ and Bertrand Isidor $^{1}$
}

\begin{abstract}
Background: Macrosomia and hypertrophic cardiomyopathy are two features often associated in neonates of diabetic mothers. We report the cases of three patients with severe macrosomia and critical hypertrophic cardiomyopathy without severely unbalanced maternal diabetes. Only three patients with those two features and no uncontrolled maternal diabetes have been previously reported.

Case presentation: The first patient was a 39-week-old girl, the second patient was a 39-week-old girl, and the third patient was a 41-week-old boy. The two French girls and the French boy had severe macrosomia and hypertrophic cardiomyopathy, leading to the death of the boy. The outcome of the two girls was favorable, with a standardization of growth curves and ventricular hypertrophy. Their mothers presented with high body mass index but no severe documented maternal diabetes; glycemic imbalance was only suspected on postnatal analyses. There was no hydramnios during pregnancy and no other environmental factor, especially toxic exposure. Their parents are from Mayotte, Guadeloupe, and Guinea-Conakry. The usual genetics causes, Beckwith-Wiedemann syndrome, and chromosomal copy number variation, were also excluded.
\end{abstract}

Conclusions: This report suggests the implication of other factors in addition to glycemic disorders, including genetic factors, in the occurrence of macrosomia and severe hypertrophic cardiomyopathy in neonates. These three original observations indicate that gynecologists and neonatologists should pay attention to neonates from mothers with a high body mass index and when maternal diabetes is not documented.

Keywords: Macrosomia, Hypertrophic cardiomyopathy, Genetic, Maternal diabetes, Case report

\section{Background}

Newborn macrosomia is defined as neonate's birthweight over $4000 \mathrm{~g}$ and is usually attributed to maternal obesity, gestational weight gain excess, and diabetes. Macrosomia may also be part of a genetic disorder, such as Beckwith-Wiedemann syndrome (BWS), Online Mendelian Inheritance in Man (OMIM) database number 130650; Simpson-Golabi-Behmel syndrome, OMIM 312870; or Perlman syndrome, OMIM 267000. Cardiomyopathy is not a common feature in those three pathologies.

Hypertrophic cardiomyopathy (HCM) can be sporadic or familial. In familial cases, all modes of inheritance are described, but an autosomal dominant manner is the most

\footnotetext{
* Correspondence: marie.vincent@chu-nantes.fr

'Service de Génétique Médicale, Hôpital Hôtel-Dieu, CHU de Nantes, 1 place

Alexis Ricordeau, 44093 Nantes, France

Full list of author information is available at the end of the article
}

common. HCM is also related to gestational diabetes mellitus (GDM), in particular when diabetes is unbalanced in late gestation [1]. HCM was identified as the most common cardiac malformation in fetuses of diabetic mothers, but severe $\mathrm{HCM}$, defined as having an end-diastolic interventricular septal thickness (IVSd) Z-score $>2$, is rarely described.

There are only a few reports in the literature of patients with macrosomia and severe HCM, for which uncontrolled GDM was not confirmed [2-4]. Here we report on three cases neonates presenting with severe macrosomia and HCM, without extreme maternal diabetes.

\section{Cases presentation \\ Patient 1}

The first patient was a 39-week-old baby girl born by cesarean section because of macrosomia. She was the firstborn of unrelated and unaffected parents from Mayotte, 
with no remarkable family history. Pregnancy was uneventful with normal ultrasounds, no hydramnios, and no toxic exposure. Her mother's height and weight were $176 \mathrm{~cm}$ and $115 \mathrm{~kg}$, giving a body mass index (BMI) of $36.5 \mathrm{~kg} / \mathrm{m} 2$. No oral glucose tolerance test (OGTT) was performed during pregnancy, but 2 days after delivery her mother's OGTT was in the normal range. Her mother's postnatal glycated hemoglobin $(\mathrm{HbA} 1 \mathrm{C}$ ) value was $7.1 \%$ (normal $<6 \%$ ), which means that her glycemia levels were probably slightly elevated during pregnancy (see details in Additional file 1: Table S1).

Patient 1's birth weight (BW) was $5660 \mathrm{~g}(+4$ standard deviation (SD)), birth length (BL) $57 \mathrm{~cm} \mathrm{(+3} \mathrm{SD),} \mathrm{and}$ her birth occipitofrontal circumference (OFC) $37.5 \mathrm{~cm}$ (+3 SD). Her Apgar score was 5 at 1 minute and 7 at 5 minutes due to cardiogenic shock with severe pulmonary arterial hypertension. A cardiac ultrasound showed a severe biventricular non-obstructive HCM, with an IVSd at $12 \mathrm{~mm}(+5.2 \mathrm{Z}$-score cardiac parameter Dubois) and virtual cavity in her left ventricle (Fig. 1a). Her clinical condition required an extracorporeal membrane oxygenation (ECMO) in emergency for 5 days. She was intubated for 11 days, with 2 days of high frequency oscillation (HFO). Metabolic investigations and cerebral magnetic resonance imaging (MRI) were normal. HCM decreased in 2 weeks and macrosomia disappeared (Fig. 2a). At 36 months, a cardiac ultrasound showed a residual hypertrophy of her left ventricle at $3 \mathrm{~mm}$, with an aspect of thick and hyperechogenic myocardium. Her weight was $15.5 \mathrm{~kg}(+1.5 \mathrm{SD})$, her length was $94.5 \mathrm{~cm}$ (+0.5 SD), and her OFC was $46.5 \mathrm{~cm}(-1.5 \mathrm{SD}$; Fig. 2a). Her psychomotor development was normal.

Patient 1's mother developed documented slight GDM during her following pregnancy, which was only treated with diet; her newborn did not have macrosomia or HCM.

\section{Patient 2}

The second patient was a 39-week-old baby girl born by cesarean section because of fetal arrhythmia and

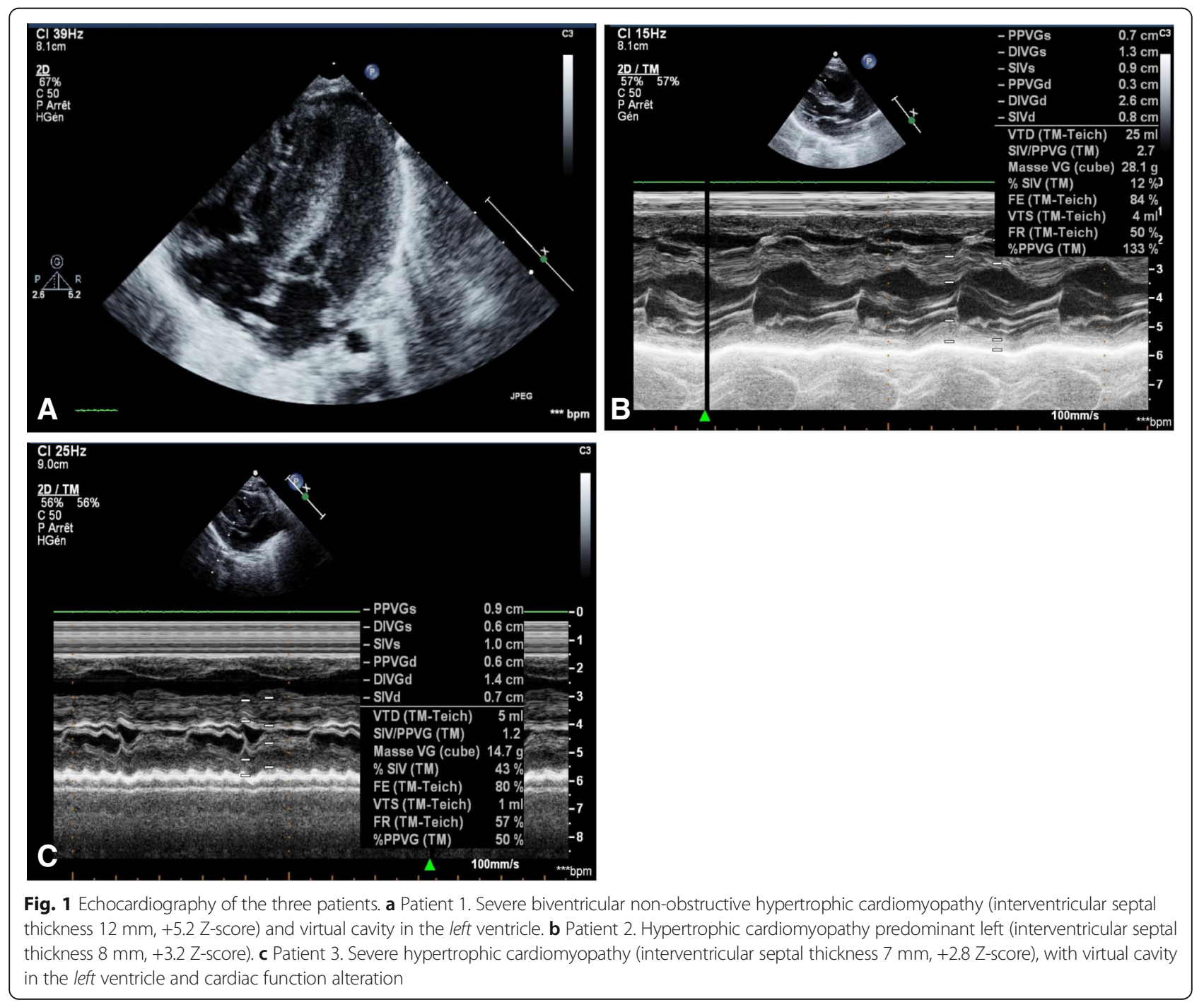




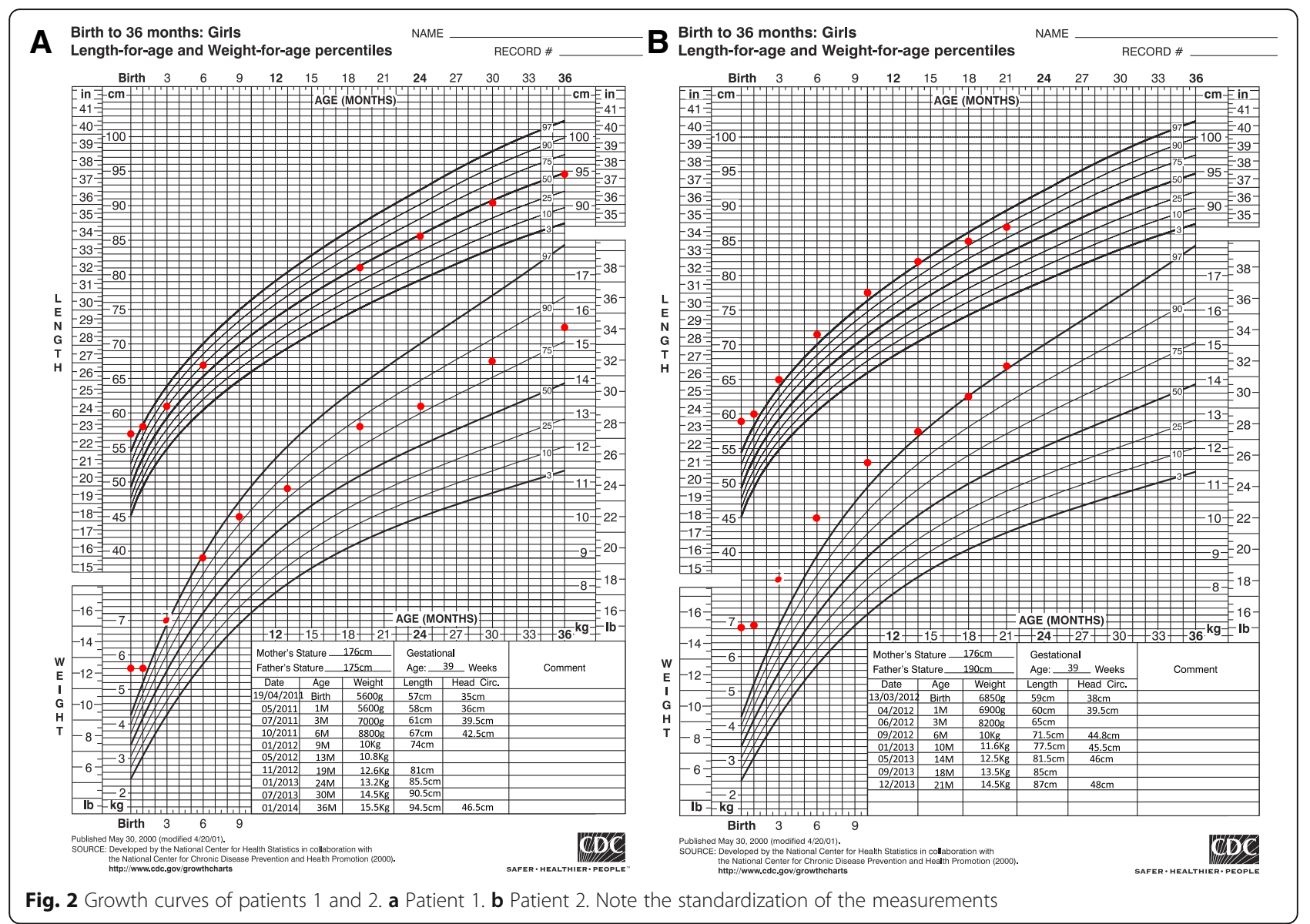

macrosomia. She was the fourth-born of unrelated and unaffected parents from Guadeloupe. Her family history was unremarkable. Her mother's and father's weight and height were $80 \mathrm{~kg}$ and $176 \mathrm{~cm}$ (BMI 25.5 $\mathrm{kg} / \mathrm{m} 2$ ), and $130 \mathrm{~kg}$ and $190 \mathrm{~cm}$. The BWs of her mother, father, and her siblings were respectively 3000 g, 4000 g, 4400 g, 4900 g and 4700 g. Pregnancy was uneventful with normal ultrasounds until 38 weeks; there was no hydramnios and no toxic exposure. Her mother's OGTT at 22 weeks was normal and $\mathrm{HbA} 1 \mathrm{C}$ was also in the normal range at $5.5 \%$ 10 days after delivery (see details in Additional file 1: Table S1).

The BW of Patient 2 was 6850 g (+6.5 SD), BL was 59 $\mathrm{cm}(+4 \mathrm{SD})$, and birth OFC was $38 \mathrm{~cm}(+3 \mathrm{SD})$. She required immediately oxygen for transient neonatal respiratory distress; a cardiac ultrasound revealed HCM (IVSd $8 \mathrm{~mm},+3.2$ Z-score cardiac parameter Dubois; Fig. 1b). Molecular analysis of BWS was negative, and deoxyribonucleic acid (DNA)-microarray was normal.

At 21 months, her weight was $14.5 \mathrm{~kg}(+3 \mathrm{SD})$, her length was $87 \mathrm{~cm}(+2 \mathrm{SD})$, and her OFC was $48 \mathrm{~cm}(+1$ SD; Fig. 2b). Her psychomotor development was normal and a cardiac ultrasound showed mild HCM.

\section{Patient 3}

The third patient was a 41-week-old baby boy born by cesarean section because of fetal arrhythmia and decreased fetal movements. He was the first-born of unrelated and unaffected parents from Guinea-Conakry. His family history was uneventful. His mother's height and weight were $173 \mathrm{~cm}$ and $80 \mathrm{~kg}$, giving a BMI of $27 \mathrm{~kg} / \mathrm{m} 2$. Antenatal ultrasounds were normal, without hydramnios, and no drug or toxic exposition was documented. There was no suspicion of maternal diabetes, so OGTT was not performed during pregnancy; his mother's OGTT was normal 3 days after delivery (see details in Additional file 1: Table S1).

His BW was $5000 \mathrm{~g}(+5.5 \mathrm{SD})$, BL $54 \mathrm{~cm}(+3 \mathrm{SD})$, and birth OFC $37 \mathrm{~cm}(+2 \mathrm{SD})$. He was born in a state of apparent death and was directly intubated for artificial ventilation with $\mathrm{HFO}$ because of refractory hypoxemia. $\mathrm{He}$ developed pulmonary hypertension at day 5 and echocardiography revealed severe HCM (IVSd $7 \mathrm{~mm},+2.8$ Z-score cardiac parameters Dubois; Fig. 1c). Several episodes of hypoglycemia were documented and a cerebral MRI revealed massive ischemic and hemorrhagic lesions. Death occurred at the fifth day of life. An autopsy was not done because of parental refusal. BWS molecular analysis was normal. 


\section{Discussion}

HCM is a well-known complication in babies of diabetic mothers [5-8], and is attributed to a compensatory increase in fetal insulin secretion. While HCM in babies of diabetic mothers is usually mild and reversible, it is rarely severe leading to fetal or neonatal death. Only five patients with severe neonatal HCM were reported previously in association with GDM [2, 3, 9-11]. Other studies showed that glucose and insulin levels were not so predictive of fetal macrosomia [12, 13].

Sardesai et al. reported the case of a fetus with fatal HCM and macrosomia. The mother had a well-controlled GDM under insulin therapy [2]. Moreover, Mehta and Hussain described another patient with transient hyperinsulinism associated with macrosomia, severe obstructive HCM, hepatomegaly, and nephromegaly in a mother with mild GDM requiring no treatment [3]. Maternal postnatal OGTT was negative, and follow-up showed an improvement of the HCM with a mild residual left ventricular hypertrophy. In those two last case reports, it seems difficult to attribute the severe features observed only to a benign GDM.

Furthermore, Godfried and coworkers reported the case of a patient with severe HCM, macrosomia (BW $5290 \mathrm{~g})$, and hepatomegaly born to a mother with human immunodeficiency virus (HIV) infection [4]. GDM and other metabolic disorders were excluded, and a relationship between the neonatal abnormalities and antiretroviral treatment was suspected. Other toxic causes have not been reported in the literature and there was no history of toxic exposure for our three patients.

Maternal diabetes was excluded in the mother of Patient 2. OGTT of the mothers of Patients 1 and 3 were not performed during pregnancy but postnatal analyses do not indicate severe glycemia disequilibrium. Even if we consider mild GDM in those two cases, this cannot explain completely, in our opinion, the severity of the children's phenotype.

The three major genetic overgrowth syndromes including BWS, Simpson-Golabi-Behmel syndrome, and Perlman syndrome, do not usually present with cardiomyopathy. Cardiomyopathy has been rarely reported in BWS [14, 15], but molecular analysis ruled out this hypothesis in Patients 2 and 3.

To date, more than 13 genes have been identified for isolated HCM. Most of them are inherited in an autosomal dominant pattern. In the present report we did not consider monogenic forms of HCM because of macrosomia, the spontaneously favorable evolution, and the absence of family history.

\section{Conclusions}

We reported the case of three patients with macrosomia and severe HCM at birth. We hypothesize that other additional factors to maternal diabetes, such as genetic and/or metabolic factors, might be involved in the determinism of this phenotype. We propose that gynecologists should perform OGTT during pregnancy in cases of high BMI, even if there is no familial history of GDM or hydramnios. We propose also that neonatologists and pediatric cardiologists pay special attention to neonates presenting with macrosomia, even if no GDM has been documented, and pay attention to other potential factors.

\section{Additional file}

Additional file 1: Table S1. Mothers' oral glucose tolerance test (OGTT) of patients 1, 2, and 3. (XLS $20 \mathrm{~kb}$ )

\section{Abbreviations}

BL: Birth length; BMI: Body mass index; BW: Birth weight; BWS: BeckwithWiedemann syndrome; ECMO: Extracorporeal membrane oxygenation; GDM: Gestational diabetes mellitus; HbA1C: Glycated hemoglobin;

HCM: Hypertrophic cardiomyopathy; HFO: High frequency oscillation; IVSd: Interventricular septal thickness; OFC: Occipitofrontal circumference; OGTT: Oral glucose tolerance test; OMIM: Online Mendelian Inheritance in Man

Acknowledgements

We are grateful to the patients and their families who participated in this study. We thank the University of Nantes who supported this publication.

Funding

The University of Nantes supported this publication.

Availability of data and materials

Data sharing is not applicable to this article as no datasets were generated or analyzed during the current study.

Authors' contributions

MV analyzed and interpreted the patient's data regarding the genetic factors of the features observed and was the major contributor in writing the manuscript. NB performed the echocardiogram and the follow up of Patients 1 and 3 . He selected the images and contributed in writing the manuscript. BR performed the echocardiogram and the follow up of Patient 2. She selected the image and contributed in writing the manuscript. SB analyzed and interpreted the patient's data regarding the genetic factors of the features observed. Bl analyzed and interpreted the patient's data regarding the genetic factors of the features observed and was the major corrector of the manuscript. All authors read and approved the final manuscript.

Competing interests

The authors declare that they have no competing interests.

\section{Consent for publication}

Written informed consent was obtained from the legal guardians of the patients for publication of this case report and any accompanying images. A copy of the written consents is available for review by the Editor-in-Chief of this journal.

Ethics approval and consent to participate

Not applicable.

\section{Author details}

'Service de Génétique Médicale, Hôpital Hôtel-Dieu, CHU de Nantes, 1 place Alexis Ricordeau, 44093 Nantes, France. ${ }^{2}$ Service de Cardiologie pédiatrique, Hôpital Mère-Enfant, CHU de Nantes, 38, boulevard Jean-Monnet, 44093 Nantes, France. ${ }^{3}$ Service de Biologie de la Reproduction, Hôpital Mère-Enfant, CHU de Nantes, 38, boulevard Jean-Monnet, 44093 Nantes, France. 
Received: 5 May 2016 Accepted: 1 February 2017

Published online: 24 March 2017

\section{References}

1. Chaudhari M, Brodlie M, Hasan A. Hypertrophic cardiomyopathy and transposition of great arteries associated with maternal diabetes and presumed gestational diabetes. Acta Paediatr. 2008;97(12):1755-7.

2. Sardesai MG, Gray AA, McGrath MM, Ford SE. Fatal hypertrophic cardiomyopathy in the fetus of a woman with diabetes. Obstet Gynecol. 2001;98(5 Pt 2):925-7.

3. Mehta A, Hussain K. Transient hyperinsulinism associated with macrosomia, hypertrophic obstructive cardiomyopathy, hepatomegaly, and nephromegaly. Arch Dis Child. 2003:88(9):822-4

4. Godfried MH, Boer K, Beuger S, Scherpbier HJ, Kuijpers TW. A neonate with macrosomia, cardiomyopathy and hepatomegaly born to an HIV-infected mother. Eur J Pediatr. 2005;164(3):190-2.

5. Way GL, Wolfe RR, Eshaghpour E, Bender RL, Jaffe RB, Ruttenberg HD. The natural history of hypertrophic cardiomyopathy in infants of diabetic mothers. J Pediatr. 1979;95(6):1020-5.

6. Tyrala EE. The infant of the diabetic mother. Obstet Gynecol Clin North Am. 1996;23(1):221-41.

7. Halliday HL. Hypertrophic cardiomyopathy in infants of poorly-controlled diabetic mothers. Arch Dis Child. 1981;56(4):258-63.

8. Weintrob N, Karp M, Hod M. Short- and long-range complications in offspring of diabetic mothers. J Diabetes Complications. 1996;10(5):294-301.

9. Franzese A, Valerio G, Ciccarelli NP, De Filippo G, lannucci MP, Alfonsi L, et al. Severe hypertrophic cardiomyopathy in an infant of a diabetic mother. Diabetes Care. 1997;20(4):676-7.

10. McMahon JN, Berry PJ, Joffe HS. Fatal hypertrophic cardiomyopathy in an infant of a diabetic mother. Pediatr Cardiol. 1990;11(4):211-2.

11. Robinson B, Eshaghpour E, Ewing S, Baumgart S. Hypertrophic obstructive cardiomyopathy in an infant of a diabetic mother: support by extracorporeal membrane oxygenation and treatment with beta-adrenergic blockade and increased intravenous fluid administration. ASAIO J. 1998; 44(6):845-7.

12. Ali MM, Brown M, Karnitis VJ. Third trimester insulin levels are not correlated with fetal macrosomia or delivery complications. J Reprod Med. 2014;59(56):293-8.

13. Guillen MA, Herranz L, Barquiel B, Hillman N, Burgos MA, Pallardo LF. Influence of gestational diabetes mellitus on neonatal weight outcome in twin pregnancies. Diabet Med. 2014;31(12):1651-6.

14. Ryan CA, Boyle MH, Burggraf GW. Reversible obstructive hypertrophic cardiomyopathy in the Beckwith-Wiedemann syndrome. Pediatr Cardiol. 1989:10(4):225-8.

15. Emery LG, Shields M, Shah NR, Garbes A. Neuroblastoma associated with Beckwith-Wiedemann syndrome. Cancer. 1983;52(1):176-9.

\section{Submit your next manuscript to BioMed Central and we will help you at every step:}

- We accept pre-submission inquiries

- Our selector tool helps you to find the most relevant journal

- We provide round the clock customer support

- Convenient online submission

- Thorough peer review

- Inclusion in PubMed and all major indexing services

- Maximum visibility for your research

Submit your manuscript at www.biomedcentral.com/submit
Biomed Central 